\title{
Trajetórias do empreendedorismo imigrante e estratégias de mercado a partir das experiências de brasileiros no exterior
}

\section{Immigrant entrepreneurship trajectories and market strategies derived from Brazilian experience overseas}

\author{
Eduardo Picanço Cruz \\ epicanco@vm.uff.br \\ Universidade Federal Fluminense - Niterói - RJ \\ Roberto Pessoa de Queiroz Falcão \\ robertopgfalcao@gmail.com \\ Universidade Federal Fluminense - Niterói - RJ

\section{Rafael Cuba Mancebo} \\ cuba.mancebo@gmail.com \\ Universidade Federal Fluminense - Niterói - RJ
}

Recebido em 14.04.2017. Aprovado em 20.08.2017

Avaliado pelo sistema double blind review

\author{
Andrea Ribeiro Carvalho de Castro \\ andrearc.castro@gmail.com \\ Pontifícia Universidade Católica do Rio de Janeiro - PUC/Rio - Rio de Janeiro - RJ
}

\section{Resumo}

O objetivo desse ensaio é o de identificar diferentes trajetórias de empreendedores imigrantes que são ilustradas através de comportamentos, e inspiradas tanto em evidências empíricas quanto nas teorias existentes a respeito do tema. Na proposta do modelo de trajetórias, destacam-se alguns fatores, como: a situação legal na entrada do país, o grau de escolaridade, experiências prévias de trabalho, proficiência na língua local, e o grau de conexão dos imigrantes, conformado dentro ou fora das comunidades étnicas. As trajetórias de cada tipo de imigração pesquisada configuram-se como caminhos únicos e possíveis. São ilustradas as trajetórias que retratam alguns tipos de empreendedores, baseados em suas histórias de vida. Os pesquisadores valeram-se da inspiração da literatura acadêmica no tema combinada com dados que emergiram do campo através de diversas técnicas de coleta - entrevistas em profundidade, observação participante, análise documental e surveys. De acordo com sua similaridade e representatividade, foram categorizadas nove possíveis trajetórias, que se configuram a partir de um processo decisório, combinando o efeito do ambiente com a história individual de cada imigrante, sendo explicadas ao longo do ensaio.

Palavras-chaves: Empreendedorismo; Empresário imigrante, Caminho empreendedor, Enclave étnico.

\section{Abstract}

The purpose of this essay is to identify different trajectories of immigrant entrepreneurs that are illustrated through behaviors, and inspired by both empirical evidence and existing theories about the subject. In the proposal of the trajectory model, we highlight some factors, such as, the legal situation at the entrance of the country, the degree of schooling, previous work experiences, local language proficiency, and the degree of connection between immigrants, conformed inside or outside of the ethnic communities. The trajectories of each type of immigration researched are configured as unique and possible paths. The authors portray the trajectories of some types of entrepreneurs, based on their life histories. The researchers drew inspiration from the academic literature on the theme, combined with data that emerged from the field through various 


\section{Eduardo Picanç,o Cruz, Roberto Pessoa de Queiroz Falcão, Rafael Cuba Mancebo e Andrea Ribeiro Carvalho de Castro}

collection techniques - in-depth interviews, participant observation, documentary analysis and surveys. According to its similarity and representativeness, nine possible trajectories were categorized, which are based on a decision-making process, combining the effect of the environment with the individual history of each immigrant, being explained throughout the essay.

Keywords: Entrepreneurship; Immigrant entrepreneur; Entrepreneurial path; Ethnic enclave.

\section{Introdução}

A direção do debate sobre imigração, em muitas nações desenvolvidas como países europeus, ou mesmo, nos Estados Unidos, tem caminhado para a radicalização. Recentemente, ordens de deportações, ou políticas de controle e vigilância sobre determinados grupos étnicos tem intensificado o debate sobre o tema. Como afirmado pelo economista norte-americano de origem cubana (Borjas, 2017): muitos imigrantes ainda sonham em construir uma vida melhor, e o fazem. Seja na América do Norte, Austrália ou Inglaterra, a política de imigração pode beneficiar enormemente as pessoas. Contudo, segundo o autor, a imigração não traz o bem-estar de todos, havendo vencedores e perdedores neste jogo de difíceis opções. Melhorar a condição de vida de imigrantes tem seu preço para as sociedades receptoras. Borjas (2017) aponta para os dois lados da questão. Por um lado, aqueles que querem mais imigração afirmam que os imigrantes se engajam em trabalhos que os americanos nativos não querem realizar. Mas o salário mais baixo de alguns é o lucro maior de outros, sendo que esse aumento da rentabilidade dos negócios de muitos empregadores gera um superávit nas economias hospedeiras, segundo o autor. Então, fica um questionamento se 0 incremento da imigração, pode sim aumentar a riqueza agregada dos americanos ou quiçá dos europeus, australianos e canadenses? No passado, na virada do século XX, havia o conceito do meltingpot norteamericano, que seria capaz de assimilar milhares de imigrantes anualmente, empregados na crescente indústria norte-americana. Muitos deles não trabalhavam nas fábricas, mas criavam suas lojas ou pequenos comércios nos ambientes urbanos, como relatado por Halter (2007). Borjas (2007, p.6) ainda afirma que 0 governo americano:

Precisa[ria] escolher entre [imigrantes] altamente qualificados e os menos qualificados. [Por um lado os altamente qualificados] pagam mais impostos [...] e expandem a fronteira do conhecimento, sendo mais lucrativos [...] embora, conceder uma oportunidade às massas amontoadas é parte do que torna [os EUA um] país excepcional.

Na atualidade, também bilhões de dólares circulam em comércios locais, cujos empreendedores são esses mesmo imigrantes, estabelecidos em enclaves étnicos (Bonacich, 1973).

Por outro lado, imigrantes altamente qualificados que entram como estudantes de $\mathrm{PhD}$ ou de outros programas de pós-graduação, engajam-se em empreendimentos de startups tecnológicas no Vale do Silício, Nova lorque, Londres e TelAviv. Ocorrem fluxos de idéias, mentes, capital e bens, promovidos por telecomunicações e meios de transporte cada vez mais rápidos e baratos. Alguns desses fluxos alcançam uma escala global. Contudo, a discussão de modelos teóricos que mapeiem os possíveis perfis dos diversos tipos de empreendedores imigrantes apresenta-se como lacuna teórica, conforme constatado em estudos bibliométricos no tema de empreendedorismo imigrante e enclaves étnicos (Ma, Zhao, Wang, \& Lee, 2013; Aliaga-Isla, \& Rialp, 2013).

A maioria dos estudos a respeito da imigração e de suas atividades empreendedoras concentra-se em imigrantes latinos, asiáticos ou do Oriente Médio que chegam à Europa, Austrália e América do Norte (por exemplo, Bonacich, 1973; Portes, \& Zhou, 1992; Light, Bhachu, \& Karageorgis, 1993; Gold, \& Light, 2000; Zhou, 2004; Elo, \& Volovelsky, 2016; Elo, Harima, \& Freiling, 2015; Emontspool, \& Servais, 2016). Alguns autores nacionais também empreenderam estudos relativos tanto à imigração quanto ao empreendedorismo de imigrantes brasileiros (por exemplo: Rocha, Esteves, Mello, \& Silva, 2015; Sasaki, 2006; Sales, 2005; Margolis, 1995). No entanto, persiste também na literatura acadêmica nacional, uma carência de pesquisas ISSN 2318-9231

CGE * v .5 * n. 2 * Mai-Ago 2017 * 37-54 


\section{Trajetórias do empreendedorismo imigrante e estratégias de mercado a partir das experiências de brasileiros no exterior}

que busquem traçar modelos teóricos ou frameworks mais abrangentes.

De um lado, estudos de negócios internacionais ensejaram traçar modelos explicativos de internacionalização de grandes empresas em estágios (Johanson, \& Vahlne, 1977, 2009), de pequenos e médios negócios que nascem globais - born globals (Madsen, \& Servais, 1997) e das international new ventures [INV]s (Oviatt, \& McDougall, 1994; McDougall, \& Oviatt, 2000). Por outro, no campo de empreendedorismo imigrante e étnico, foram encontrados na literatura internacional poucos estudos que almejassem uma teorização de seu processo(por exemplo, Kloosterman, \& Rath, 2001; Ibrahim, \& Galt, 2003; Volery, 2007). Ainda, no tocante às possíveis trajetórias empreendedoras não se encontrou tampouco nenhum framework teórico consolidado, embora se destaquem nesse campo os trabalhos que traçam possíveis tipologias de empreendedores (Fillion, 1999) ou que mapeiam os caminhos de imigrantes desde sua intenção de migrar até conseguirem emprego e decidirem empreender (Knight, 2015). Assim sendo, uma lacuna teórica apontada por autores como Portes e Zhou (1992), Zhou (2004) e Aliaga-Isla e Rialp (2013), seria a de um modelo teórico que explique possíveis perfis dos empresários imigrantes, destacando as relações entre suas redes, conformadas em comunidades étnicas e transnacionais.

Dessa forma, o objetivo desse ensaio é o de identificar diferentes trajetórias de empreendedores imigrantes que são ilustradas através de comportamentos, e inspiradas tanto em evidências empíricas quanto nas teorias existentes a respeito do tema. Assim, os autores optaram por usar como arcabouço teórico três estudos que fundamentam o fenômeno da imigração ligada ao empreendedorismo: Portes e Zhou (1992), que discutem a questão da assimilação e empreendedorismo de latinos e chineses; Zhou (2004) que aborda as trajetórias de imigrantes empreendedores chineses em Chinatown e Knight (2015) que desenha as trajetórias comuns de poloneses que imigram para a Grã Bretanha, mostrando as etapas da chegada no país hospedeiro, busca de moradia, obtenção de emprego e decisão de empreender.

Além da literatura acadêmica consultada, evidências empíricas foram coletadas dentro das comunidades brasileiras, devido à acessibilidade aos empreendedores e demais stakeholders. Vale ressaltar que o Brasil, por ser uma nação cujas raízes culturais derivam de uma miscigenação racial (Freyre, 1986), de povos de várias origens étnicas (De Holanda, Summ \& Monteiro 2012), tem particularidades interessantes. O país se enquadra tanto em uma nação historicamente receptora de imigrantes, quanto na categoria de país emissor. Atualmente, o Brasil se apresenta como nação anfitriã de refugiados e imigrantes haitianos, angolanos, sírios, peruanos e bolivianos. Não obstante, outras nações mundiais também se enquadrariam em características semelhantes, embora não seja o objetivo deste ensaio detalhar as demais possibilidades.

Para criação do modelo teórico, buscou-se relatar as possíveis trajetórias empreendedoras realizadas pelos diversos empreendedores imigrantes. Como consequência da reflexão do modelo neste ensaio, espera-se contribuir para uma maior compreensão dos perfis de empreendedorismo, realizados por imigrantes, enriquecendo o debate a respeito da imigração e suas atividades empreendedoras. Esta perspectiva poderá também iluminar linhas teóricas que ignoram a criação de riqueza gerada pelos imigrantes (Zhou, 2004), enfatizando apenas os problemas por eles gerados. $O$ estudo aprofundado do fenômeno do empreendedorismo imigrante é rico e multidisciplinar. Algumas possibilidades de investigação futuras compreendem o estudo de born globals fundadas por imigrantes (Vilicic, 2017), em conexão com seus clientes (Saxenian, 2007), o estudo da análise de vantagens competitivas (Barney, 1991)derivadas de suas escolhas estratégicas (Mintzberg, 1988), de seu estabelecimentos disputando recursos e mercados com as firmas nacionais, internacionais e globais (Zolin \& Schlosser, 2013; Tung, 2008) e das barreiras ao empreendedorismo (Schoof, 2006; Gorji, \& Rahimian, 2011).

\section{Referencial Teórico}

\section{Fluxos Migratórios e suas particularidades}

O conceito internacional descrito no Glosario sobre Migración (2006) da Organização Internacional para as Migrações [OIM], destaca que, fluxos migratórios são movimentos de uma população para outros territórios, 


\section{Eduardo Picanç,o Cruz, Roberto Pessoa de Queiroz Falcão, Rafael Cuba Mancebo e Andrea Ribeiro Carvalho de Castro}

estados ou nações. Eles configuram-se independentemente do tamanho, composição ou causas, incluindo a migração de refugiados, pessoas deslocadas, pessoas desarraigadas, migrantes econômicos. Nesse sentido, é importante ressaltar que mais de $3 \%$ da população mundial era composta por cidadãos imigrantes, sendo que esse número saltaria para $10 \%$ na composição de países desenvolvidos (Riddle, 2008).

Conjugando os textos de Teixeira, Braga, \& Baeninger (2012), Ferreira (2016) e Massey, Arango, Hugo, Kouaouci, Pellegrino, \& Taylor (1993), entre outros, podemos classificar os movimentos migratórios de acordo (i) com a motivação: emigrantes - causas relacionadas ao local de origem (área repulsiva), ou imigrantes - causas relacionadas ao local de destino (área atrativa); (ii) com a duração: temporárias ou definitivas; (iii) com o espaço geográfico: internas ou externas; (iv) com a forma: voluntária ou forçada; e (v) com os mecanismos de controle: legais ou clandestinos.

Especificamente as migrações temporárias que traduzem fenômenos abordados no presente artigo dizem respeito aos vistos de executivos expatriados, trabalhadores ou estudantes. No caso dos brasileiros, Sasaki (2006) estudou esse tipo de imigração entre os descendentes de japoneses que foram trabalhar em fábricas do Japão. Sales (2005) e Margolis (1995) descreveram fluxos de imigração temporária de brasileiros nos EUA. Cruz, Jesus, Falcão, Lopes, Petri, Melo e Junior (2016) destacaram o caso dos estudantes brasileiros na Austrália.

Já no tocante à imigração definitiva, foram identificados dois casos: (i) reivindicar cidadania por ancestralidade - presente, por exemplo, nos casos de descendentes de europeus; (ii) saída por questões afetivas, como os casos de imigração por matrimônio identificados por Cruz et al (2016).

Sobre a condição legal é classificado como 'estrangeiro indocumentado' aquele que entra ou permanece num país sem a documentação necessária. Esta condição inclui, entre outros

(a) quem ingressa clandestinamente sem a documentação para entrar no país; (b) quem entra utilizando documentação falsa; (c) quem, após ter ingressado com a documentação legal, permanece no país após o tempo autorizado ou, se tiver violado as normas de ingresso, permanece sem autorização do imigrante (Glosario sobre Migración, 2006, p.26).

Para imigrantes capitalizados, que desejam utilizar seus recursos para 'comprar uma cidadania' ou qualquer condição de regularidade correlata, alguns países oferecem programas especiais como o exemplo dos EUA, destacados por Cruz, Falcão e Barreto (2017). Os autores identificaram que alguns empresários brasileiros buscando internacionalizar seus negócios estavam, na verdade, interessados no processo de imigração. Para esses empresários uma opção é o visto de investidor: EB-5 (Quaino, 2015). Informações oficiais norteamericanas, apresentadas pelos autores, destacam que entre 1997 e 2013 o Brasil foi responsável por 25\% das solicitações de visto de não imigrantes da América Latina. Outro programa similar foi o de incentivo migratório de investidores chineses para o Canadá (Ley, 2017), o qual promoveu uma dinamização do mercado imobiliário de cidades como Vancouver e Toronto.

A discussão sobre os fluxos migratórios ganha cada vez mais espaço na mídia haja vista o fluxo de refugiados do Norte da África e do Oriente Médio que impactam as nações receptoras, bem como todo 0 debate provocado no sentido de revisar políticas públicas de governos norte-americanos e europeus. Apesar da atualidade, a discussão sobre a assimilação de imigrantes não é nova. As comunidades de imigrantes sempre foram vistas com reserva pelas sociedades acolhedoras. Teorias como a anglo conformity, meltingpot e a da pluralidade cultural tentaram explicar o processo de assimilação das comunidades imigrantes ou, pelo menos, entender as particularidades de alguns grupos (Gordon, 1961).

O debate floresceu na área das ciências sociais, principalmente no que diz respeito aos estudos sobre pobreza dos grupos étnicos. Havia uma crença de que somente abandonando sua cultura, e sendo completamente assimiladas pela sociedade acolhedora, é que as minorias poderiam ascender economicamente. No entanto, à medida que esses grupos foram se tornando auto-suficientes, interagindo entre si, reforçando sua cultura e estilo de vida, eles desenvolveram inclusive sentimentos de fidelidade às 


\section{Trajetórias do empreendedorismo imigrante e estratégias de mercado a partir das experiências de brasileiros no exterior}

suas tradições étnicas (Portes, \& Zhou, 1992).

Outro conceito importante de pontuar é a diferenciação entre imigrante e étnico. Bonacich (1973), assim como Light, Bhachu, \& Karageorgis (1993) diferenciam o imigrante como sendo aqueles que migraram, ou estrangeiros, pertencentes à primeira geração. Já os indivíduos pertencente à uma minoria étnica referemse aos descendentes dos imigrantes - da segunda geração em diante. De forma genérica, adotaremos nesse artigo o termo 'imigrante' para designar os grupos imigrantes ou étnicos.

\section{Empreendedorismo de Imigrantes}

De acordo com Halter (2007) uma significativa parcela dos pequenos negócios de vários países da atual sociedade ocidental é ocupada por empreendedores étnicos. Baseado na história dos EUA, a autora destaca que no século XIX as principais cidades receptoras de estrangeiros tinham grande percentual de negócios fundados por imigrantes, sendo que esse fenômeno ainda é presente nos dias atuais.

Dentre as diversas questões levantadas por Halter (2007), os negócios étnicos envolvem características culturais distintivas que contribuem para o sucesso de um empreendimento. Drori, Honig e Wright (2009) conceituam empresários étnicos como aqueles ligados às suas comunidades por laços culturais, diferenciando-os de empresários transnacionais, que retornam ou empresários internacionais. Já Light, Sabagh, Bozorgmehr, e Der-Martirosian (1994) destacam que os negócios étnicos têm maior propensão de sucesso quando se materializam dentro dos enclaves étnicos. Sobre esse assunto, Halter (2007) enfatiza algumas características dos enclaves étnicos, as quais corroboram com achados de Zhou (2004), e que serão descritas também a partir de outros estudos apresentados a seguir.

Portes e Zhou (1992), assim como Cruz, Falcão e Barreto (2017) e Logan, Zhang e Alba (2002), dentre outros, destacaram a importância do enclave étnico como vórtices para o fomento de pequenos negócios. Em um processo gradual, os enclaves fornecem espaço para o desenvolvimento de uma comunidade imigrante mais forte. Nesse sentido estas grandes concentrações de moradias e negócios étnicos constituem nichos de mercado dentro dos mercados nacionais. Eles representam locais de interação entre membros de uma comunidade étnica, onde as habilidades culturais e sociais dos imigrantes são combinadas para a criação de pequenos negócios, derivados de um capital humano (Bourdieu, 1986) específico e disponível na comunidade étnica. Esses negócios, em geral de pequeno e médio porte, geram empregos formais ou informais, fundamentais para assimilação econômica de imigrantes excluídos do mercado de trabalho de seus países de acolhimento (Drori, Honig, \& Wright, 2009). A disponibilidade de trabalhadores étnicos frequentemente informais, que aceitam salários mais baixos, promovem maior competitividade de custo às pequenas firmas. Contudo, alguns dos trabalhadores, após anos de trabalho em condições inferiores, podem decidir por montarem seus próprios negócios. Os enclaves, além de um local de disseminação da cultura étnica (comidas, vestuário e bebidas típicas), são também um canal para a disseminação de práticas de negócios, acesso à informações sobre mercados-chave ou a fornecedores específicos e confiáveis. Adicionalmente, as comunidades étnicas também podem ajudar os empreendedores através de mecanismos informais de crédito, como relatado por Light, Bhachu, \& Karageorgis (1993). O "empreendedorismo étnico", que muitas vezes surge nos enclaves de imigrantes, pode ser considerado como um veículo alternativo de mobilidade econômica (Portes, \& Zhou, 1992). Outra característica comum aos enclaves, também relatada por esses autores é a "solidariedade limitada ao grupo" ou "confiança limitada" - uma espécie de "rede de proteção" que se manifesta nas seguintes características: (i) como consumidores, os indivíduos da mesma etnia favorecem os itens associados ao seu país de origem, tanto em termos da utilidade do bem como da representação simbólica - refletindo a identidade do seu povo; (ii) como trabalhadores, muitas vezes preferem trabalhar entre si, podendo falar sua própria língua, embora isso muitas vezes signifique receber menores salários; e (iii) como investidores, eles se envolvem em práticas de "transnacionalismo" ou optam por investir seu capital na própria comunidade étnica.

Apesar de grande parte dos autores (por exemplo, Portes, \& Zhou, 1992; Gold, \& Light, 2000; Elo, Harima, 


\section{Eduardo Picanç,o Cruz, Roberto Pessoa de Queiroz Falcão, Rafael Cuba Mancebo e Andrea Ribeiro Carvalho de Castro}

\& Freiling, 2015; Elo, \& Volovelsky, 2016; Emontspool, \& Servais, 2016), enfatizem aspectos sociológicos do enclave étnico, pode-se também fazer uma conexão com pesquisas relacionadas ao impacto das redes de apoio aos imigrantes durante a concepção empresarial (Saxenian, 2007). As redes sociais são baseadas em conexões com consumidores e alianças inter-organizacionais que influenciam a co-criação de oportunidades através da articulação de disputas (Brinkerhoff, 2016).

\section{Trajetórias empreendedoras e empreendedorismo imigrante}

Para Born (2001) trajetória de vida refere-se a um conjunto de eventos que fundamentam a vida de uma pessoa. A autora afirma que esta é normalmente determinada pela frequência dos acontecimentos, pela duração e localização dessa existência ao longo de uma vida.

Já Kohli (1985), vincula a trajetória da vida moderna com o sistema de emprego dos indivíduos, sugerindo uma divisão em três estágios: (i) preparação para o trabalho; (ii) atividade econômica; e (iii) aposentadoria. Aos indivíduos que optam por uma carreira empreendedora, o emprego seria substituído por esta atividade.

Knight (2015), em um trabalho que inspirou esse ensaio, aborda as trajetórias de trabalho e empreendedorismo dos imigrantes poloneses que migraram para o Reino Unido, após a entrada do país na União Européia. A autora descreve a conformação dos enclaves, das empresas étnicas que empregam seus compatriotas poloneses. Ela discute quais seriam as motivações dos imigrantes ao se tornarem empresários étnicos e dos que são contratados por empresas como trabalhadores co-étnicos. Usando dados obtidos através de entrevistas semi estruturadas com migrantes poloneses em Cardiff, a autora desenha as trajetórias que se concentram nas mudanças de motivações e características desses migrantes ao longo do tempo. Segundo Knight (2015), a partir de seus achados, a aquisição do capital humano pelos migrantes no país de destino, juntamente com o uso de sua rede social (network), são as principais diferenças entre os imigrantes que escolheram o empreendedorismo étnico e os que optaram pelo emprego co-étnico. Os diagramas das trajetórias apresentados neste estudo serviram como uma das fontes de inspiração do presente ensaio, o qual buscou traçar uma figura maior e mais completa das diferentes possibilidades de trajetórias imigrantes.

\section{Procedimentos metodológicos}

Escolheu-se o método de ensaio teórico dado que sua "forma ensaística é a forma como são incubados novos conhecimentos, até mesmo científicos ou pré-científicos" (Meneghetti, 2011, p.323). Além das fontes de literatura acadêmica consultada e enunciada na seção de "Referências Teóricas", os pesquisadores valeram-se de uma robusta coleta de evidências por meio de várias estratégias, ao longo de seis anos de campo, conforme demonstrado na tabela 1.

\begin{tabular}{|c|c|c|}
\hline Fase 1 - 2010 - 2012 & Fase 2 - 2012 - 2015 & Fase 3 - A partir de 2016 \\
\hline $\begin{array}{ll} & \text { - Pesquisa } \\
& \text { exploratória } \\
\text { - } & \text { - Observações nos } \\
& \text { enclaves étnicos } \\
\text { - } & \text { - Análise de } \\
& \text { documentos }\end{array}$ & $\begin{array}{ll}\text { - } & \text { - Observações nos } \\
& \text { enclaves étnicos } \\
\text { - } & \text { - Viagens para pesquisa } \\
& \text { de campo e entrevistas } \\
& \text { de profundidade } \\
\text { - } & \text { - Triangulação } \\
\text { - } & \text { - Análise de documentos }\end{array}$ & $\begin{array}{ll}\text { - } & \text { - Pesquisas netnográficas } \\
\text { - } & \text { - Survey online } \\
\text { - } & \text { - Entrevistas por telefone } \\
\text { - } & \text { - Pesquisa bibliométrica } \\
\text { - } & \text { - Revisão de literatura } \\
\text { - } & \text { - Novos estudos } \\
& \text { exploratórios }\end{array}$ \\
\hline
\end{tabular}

Tabela 1: Método de coleta de dados em cada fase da pesquisa

Fonte: Elaboração própria. 


\section{Trajetórias do empreendedorismo imigrante e estratégias de mercado a partir das experiências de brasileiros no exterior}

Os autores do presente ensaio, ao buscarem compreender os padrões de comportamento de empresários imigrantes da diáspora brasileira em todo o mundo, utilizaram a coleta de evidências através de: (i) realização de observações participantes de três comunidades de imigrantes na Flórida - Orlando, Pompano Beach e Doral, incluindo entrevistas em profundidade com 90 empresários durante quatro anos, utilizandose o método de entrevista em profundidade de McCracken (1988), que visa acessar o lado pessoal, privado ou íntimo da memória dos empreendedores imigrantes; (ii) triangulação com as partes interessadas da comunidade, tais como advogados, líderes comunitários e contadores, num total de 12 profissionais; (iii) pesquisa bibliométrica que identificou 676 artigos relevantes, 30 principais periódicos que publicam o tema 'empreendedorismo imigrante'; (iv) uma pesquisa através do método de survey com 610 brasileiros na Austrália; (v) contatos via Skype e e-mail com 15 imigrantes brasileiros-japoneses que vivem no Japão; (vi) videoconferências com três empresários judeu-brasileiros que se aventuram em Israel; (vii) análise documental de sites e fan-pages de três comunidades virtuais do Facebook - brasileiros em Sidney, brasileiros em Ibiza e brasileiros no Japão; (viii) entrevistas em profundidade realizadas com outras etnias no Brasil: haitianos, sírios, ganense e italiano. Complementação com leitura de artigos de jornal e artigos científicos, que relatam trajetórias de imigração; (ix) confronto com literatura existente sobre comunidades brasileiras (por exemplo, Bloem, 2015, Margolis, 1995; Martes, \& Rodriguez, 2004; Sasaki, 2006; Sales, 2005; Rocha et al., 2015).

\section{Modelo proposto de identificação de trajetórias referentes aos empreendedores imigrantes}

O modelo proposto emergiu a partir de uma reflexão teórica derivada das evidências coletadas através das diferentes estratégias, em conjunto com a observação participante de diversas comunidades de brasileiros no exterior, e confrontada com outros estudos no tema. Os pesquisadores buscaram utilizar variáveis relevantes e emergentes de aspectos migratórios presentes na seção 2: situação jurídica, capacidade de comunicação na língua local e tipo de ocupação que tiveram em seus primeiros anos na comunidade: emprego, subemprego ou empreendedorismo.

A fim de ilustrar as diferentes trajetórias, os pesquisadores partiram das características derivadas do processo iterativo entre teoria e dados do campo, procedendo a organização das várias trajetórias possíveis dos empresários imigrantes. Embora não se proponha esgotar essa discussão, o presente texto aprofunda 0 entendimento do processo empreendedor em diferentes contextos vivenciados por imigrantes.

A figura 1 apresenta uma árvore com as trajetórias identificadas pelos autores. Cabe reforçar que o objetivo do presente artigo diz respeito às trajetórias que findam em atividades empreendedoras dos imigrantes, assim sendo, aquelas casos onde não há empreendedorismo não foram considerados nas descrições. 


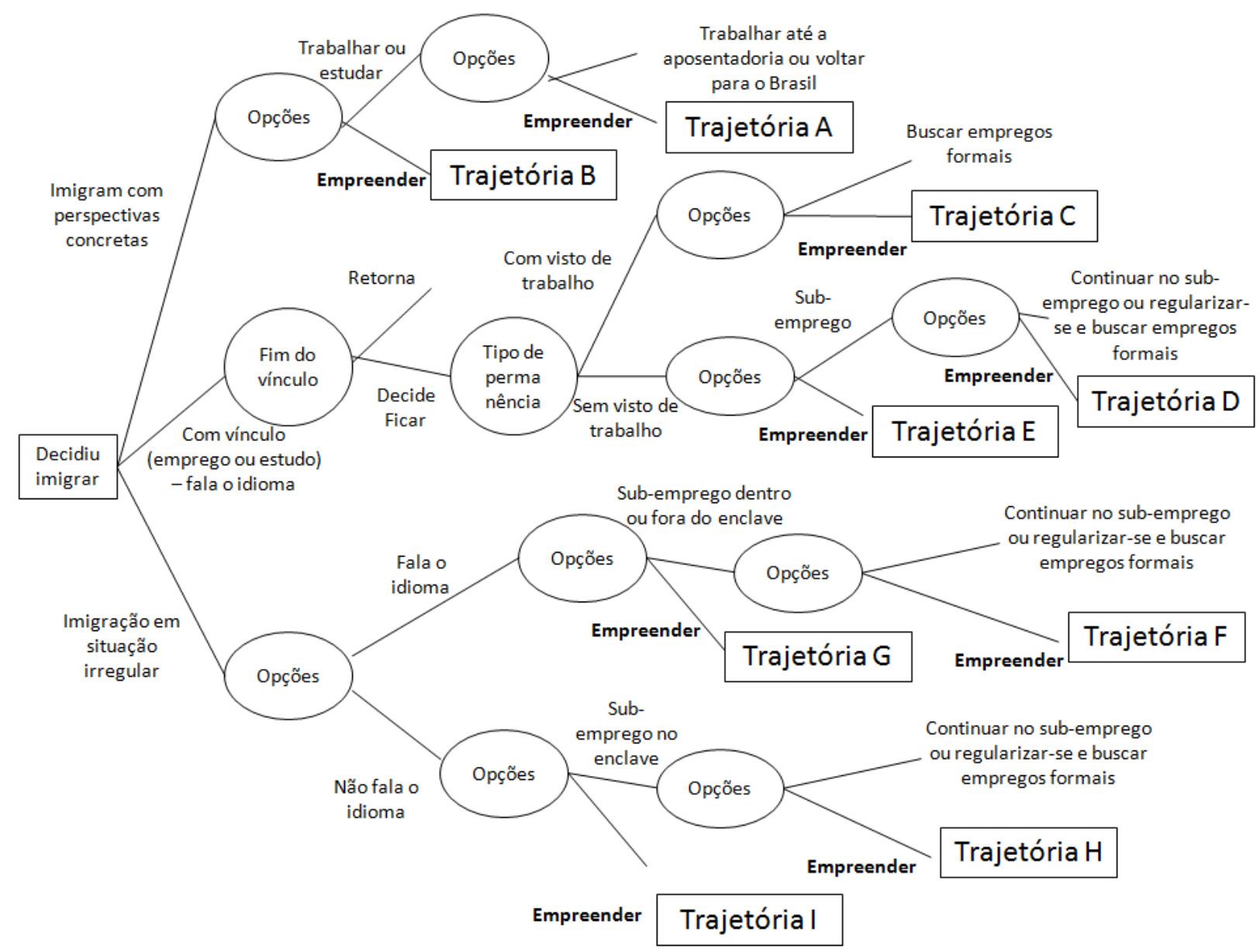

Figura 1: Modelo de trajetórias de empreendedorismo imigrante Fonte: Elaboração própria.

O primeiro aspecto destacado para caracterizar as trajetórias foi o motivo da imigração. Nesse sentido os autores fazem a apresentação das trajetórias na seguinte ordem: (i) discutindo as principais formas de imigração apresentadas na literatura ou identificadas através dos dados empíricos; (ii) identificando e classificando cada uma das trajetórias decorrentes das diferentes formas de ingresso no país receptor.

Os autores propõem três principais formas de entrada nos países receptores, realizadas por parte dos imigrantes:

a) Os que imigram com perspectivas concretas de legalização: envolvendo aqueles que contraíram matrimônio ou estão na expectativa das núpcias, aqueles descendentes que recorrem à sua ancestralidade para garantir sua condição de cidadão legal, ou os refugiados que chegam legalmente nos países que possuem programas estruturados de acolhimento.

b) Os executivos expatriados ou estudantes: envolvendo movimentos migratórios geralmente de caráter temporário. Algumas evidências destacadas por estudos como o de Cruz et al (2016), no entanto identificaram que alguns indivíduos que muitos indivíduos que deixam temporariamente seus países para estudar no exterior, têm, na verdade, pretensões de se fixarem em seus países de acolhimento. As características principais desses indivíduos são a capacidade de comunicação na língua estrangeira e uma boa formação acadêmica.

c) Os que chegam exclusivamente de forma irregular: envolvendo, normalmente um fenômeno de emigração (causa repulsiva) e caracterizada por indivíduos que fogem de seus países devido às condições inóspitas como guerra, fome, perseguição política ou religiosa. Outro perfil possível, mas 


\section{Trajetórias do empreendedorismo imigrante e estratégias de mercado a partir das experiências de brasileiros no exterior}

menos extremo dentro desta forma de entrada, são os migrantes econômicos - aqueles que buscam fugir de duras condições econômicas que afetam a qualidade de vida, como a dificuldade para se conseguir emprego, inflação alta, ou baixa qualidade dos serviços públicos como saúde e educação. Muitos não falam a língua do país de acolhimento e se valem dos enclaves étnicos para buscarem condições que, mesmo sofriveis, são melhores do que as dos países onde nasceram.

Apresentada a questão sobre o modo de entrada, os autores focam nas trajetórias empreendedoras relativas a cada uma das três opções relatadas.

\section{Os que imigram com perspectivas concretas de legalização}

Retomando a relação entre trajetória de vida e emprego/empreendedorismo, sugerida por Kohli (1985), uma vez que o imigrante se encontra em 'terras estrangeiras', tem início uma nova etapa de vida que, certamente levará ao debate sobre qual atividade econômica deve ser desenvolvida no novo país.

Países como Portugal oferecem visto de residência para aposentados ou titulares de rendimentos. (Santos, 2013). Nesses casos é possível acreditar que o imigrante dispense uma atividade econômica no país hospedeiro, desde que sua remuneração seja suficiente para arcar com suas despesas.Ao contrário disso, os imigrantes que buscam atividades econômicas podem tentar obter um emprego formal, dada sua condição legal, ou podem estudar para qualificarem-se para novas oportunidades de emprego. A outra via de atividade econômica é o empreendedorismo imediato, conforme destacado na Figura 2, que exibe um recorte da Figura 1.

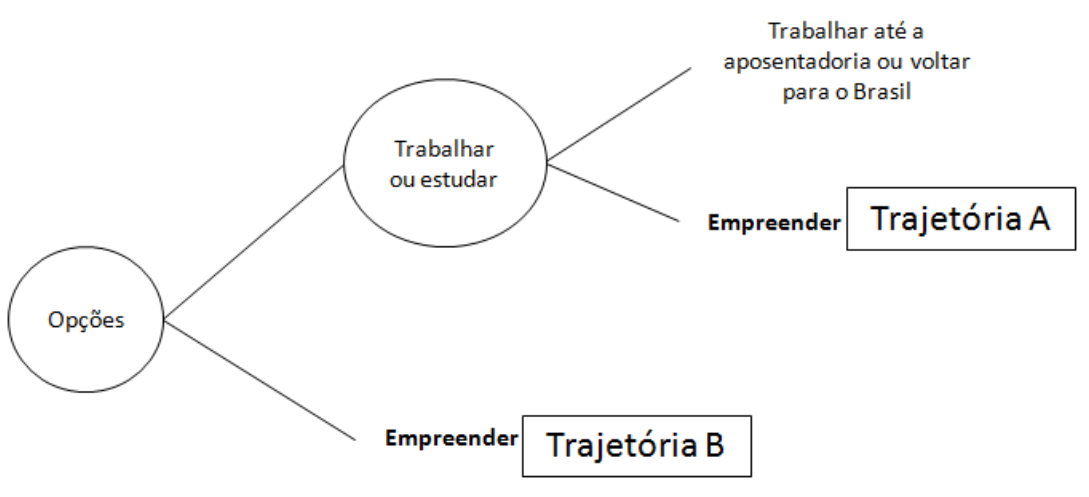

Figura 2: Possíveis atividades econômicas para os que imigram com perspectivas concretas de legalização Fonte: Elaboração própria.

A trajetória B se torna mais indicada para imigrantes com experiências anteriores de migrações temporárias, isto por que entender o modus operandi dos negócios é fator crucial para a abertura de novos negócios (Kloosterman, Van der Leun, \& Rath, 1998; Volery, 2007). Durante as investidas dos autores aos diversos campos de pesquisa, foi possível entrevistar, em 2017, um empresário de origem ganense no Brasil com essas características. Ele trabalhava com exportação de cacau em Gana, saiu com 26 anos rumo a Cabo Verde, onde abriu um restaurante. Após um tempo morando neste país decidiu fechar o negócio e vir para - Brasil. 0 empresário chegou ao Rio de Janeiro, documentado (legalizado) e decidiu montar uma loja de sapatos em na cidade de Maricá. Apesar de pouco conhecer o mercado brasileiro, este empresário entendia do negócio que abriu e sabia as principais atividades de um empreendedor.

Esses empreendedores podem ou não buscar negócios dentro de enclaves étnicos. Certamente, dada a quantidade de estudos sobre empreendedorismo étnico de enclave, os autores estão convictos de que essa seria a melhor oportunidade para os que chegam a um país e decidem empreender imediatamente. Esse 


\section{Eduardo Picanç,o Cruz, Roberto Pessoa de Queiroz Falcão, Rafael Cuba Mancebo e Andrea Ribeiro Carvalho de Castro}

comportamento se repetirá nas trajetórias $\mathrm{G}$ e I.

O exemplo dos chineses também é bem ilustrativo. Muitos conseguem imigrar com documentação regular encontrando nas chinatowns uma oportunidade para abrirem seus negócios, os quais requerem pouco capital para investimento. Os mesmos se valem do apelo étnico e das redes de relacionamento para conquistarem clientes ou recrutarem colaboradores (Portes, \& Zhou, 1992). Nas comunidades chinesas, como destacam Carvalho e Silva e Yen-Tsang (2015), uma complexa rede de relacionamento se configura. É chamada de guanxi, que vincula favores recebidos e oferecidos, de forma voluntária, por membros da comunidade. No ramo dos negócios, ter guanxi significa também ter acesso à fontes alternativas de crédito e apoio na logística de fornecimento de produtos. O guanxi chinês não acontece apenas nas economias de enclave como chinatowns, mas em qualquer cidade onde haja alguma concentração destes nacionais. Isso certamente ajuda a explicar a rápida ação empreendedora desses indivíduos no exterior - condizentes com a trajetória $\mathrm{B}$.

Por outro lado, imigrantes podem usar o trabalho ou período de estudo (qualificação) para identificarem oportunidades de negócios no exterior. A atividade empreendedora de imigrantes que deixaram seus países com perspectivas concretas de legalização, e que gastaram algum tempo aprendendo sobre as redes de fornecedores locais, legislações específicas e, acima de tudo, penetrando na rede de negócios traduz-se na trajetória A.

Os autores identificam que a experiência no país estrangeiro antes de empreender (presentes também nas trajetórias C, D, E, F e H da figura 1) ajuda a reduzir o que Johanson e Vahlne (2009) conceituaram como liabilities of outsidership, ou seja, as barreiras que a nova empresa tem que superar por não fazer parte da rede local.

Dentre vários casos estudados na literatura ou identificados nas pesquisas de campo, os autores apresentam o caso de um empreendedor na área de Miami que chegou aos Estados Unidos com 13 anos, junto com a mãe. Ela imigrou por causa de um relacionamento conjugal com um americano. Após completar os estudos nos EUA, trabalhou em algumas empresas locais, até decidir abrir o seu próprio negócio devido a oportunidades identificadas: "a idéia era ter uma empresa, um nome jurídico, junto com meu irmão, para a gente fazer alguns negócios de trading" (P., 33 anos, empresário de Miami).

\section{Os executivos expatriados ou estudantes}

No contexto do mundo globalizado e da intensa internacionalização de negócios muitas empresas dependem de colaboradores qualificados para a gestão de suas operações. Assim, a presença de executivos expatriados está cada vez mais em pauta dessas empresas transnacionais. Para Caligiuri (2000) expatriado é o executivo enviado por uma multinacional para viver e trabalhar em um país estrangeiro por período superior a um ano.

A articulação criada pelos executivos expatriados na sociedade que o recebe, temporariamente, pode ser a pedra angular onde se estabelecerá uma futura imigração definitiva. Alguns fatores colaboram com essa decisão de ficar: (i) muitas vezes o tempo que esse colaborador precisa vincular-se no exterior exige algum tipo de legalização; (ii) o processo de assimilação cultural (Gordon, 1964), além de criar laços afetivos com os membros da sociedade que o acolheu, gera uma incompatibilidade entre os novos hábitos adquiridos e a impossibilidade da nação mãe em atendê-los. Muitos brasileiros que vivem durante muitos anos nos EUA relatam a dificuldade de se adaptarem com elementos da cultura brasileira, como por exemplo, o jeitinho; (iii) executivos (as) solteiros (as) que deixam seus países podem se envolver em relacionamentos amorosos que permitam a legalização ou mesmo um pedido de cidadania.

O mesmo fenômeno da globalização que faz movimentar executivos também influencia estudantes do mundo inteiro que se engajam em programas de intercâmbio. 0 Ministério do Turismo brasileiro vincula 0 conceito de Turismo de Estudos e Intercâmbio com a motivação por atividades e programas de aprendizagem pessoal ou profissional (Brasil - Ministério do Turismo, 2010). 


\section{Trajetórias do empreendedorismo imigrante e estratégias de mercado a partir das experiências de brasileiros no exterior}

Cruz et al (2016) evidenciaram que muitos estudantes procuram programas de intercâmbio buscando uma desculpa para a imigração. No caso dos brasileiros os principais destinos são Austrália e Canadá. Durante o período no exterior, muitos estudantes usam o tempo livre para buscarem formas de se manterem e permanecerem nos países, seja através de um emprego sólido ou de um relacionamento afetivo, culminando em matrimônio. Dicas para a permanência definitiva são postadas em grupos de intercambistas no Facebook, tendo sido, diversas delas, coletadas pelos autores deste artigo. Essas postagens incluem dicas de obtenção de visto, ofertas de empregos temporários, de moradias ou quartos em apartamentos de brasileiros.

No entanto, só é possível classificar as trajetórias empreendedoras de executivos expatriados ou de estudantes a partir de sua decisão de ficar. Destaca-se que foram identificados, nas observações empíricas, negócios temporários que eram gerenciados como uma atividade complementar, tais como: aulas de violão, de idiomas, faxina, venda de bolos ou salgadinhos para aniversário, mas todos foram classificados como negócios informais, ficando de fora do modelo de trajetórias.

Os autores diferenciam as trajetórias destes indivíduos a partir de duas formas de permanência no país: os com vistos de trabalho e os sem permissão para trabalhar.

A trajetória C (figura 3) descreve o empreendedorismo de um imigrante que se enquadra nas condições descritas (expatriado ou estudante) que decide ficar, mas que detêm o visto de trabalho. Nesse caso, foram incluídos aqueles que decidem empreender ao invés de buscar outro tipo de emprego formal. Empreendedores que percorrem essa trajetória têm o grande 'leque de opções' de negócios, não se limitando à existência do mercado étnico. Como exemplo coletado na pesquisa empírica, os autores destacam o caso de um engenheiro brasileiro que, entre idas e vinda para a Califórnia - quanto trabalhava em projetos específicos da Siemens, acabou ficando até se legalizar. Em seguida, aproveitou da sua rede de contatos estabelecida, sua expertise e oportunidade para abrir seu próprio negócio. 0 curioso é que 0 negócio envolvia fornecedores americanos e asiáticos, sendo criado um negócio transnacional por um brasileiro de origem alemã, baseado nos Estados Unidos, com filiais na Ásia - um típico negócio globalizado.

Quando executivos ou estudantes resolvem ficar no país de acolhimento, mesmo sem permissão para trabalhar, o empreendedorismo (trajetória $E$ da figura 3) passa a ser uma boa alternativa. A atuação no enclave, reforçada por suas redes de relacionamento com outros nacionais, tende a ser uma opção viável, uma vez que este é o 'lar' de negócios flexíveis que requerem baixo capital (Portes \& Zhou, 1992). Slogans como 'Buy a franchise and settle down in the USA' são formas de se convencer um ex-executivo expatriado, capitalizado, a permanecer nos EUA (Whichfranchise.Com, 2016).

A outra opção para aquele indivíduo que decidiu ficar, mas não possui permissão para trabalhar é buscar um sub-emprego. Nesse caso, existem opções dentro ou fora do enclave. Não são apenas as empresas étnicas que contratam trabalhadores sem autorização para trabalhar, mas os sentimentos de solidariedade encontrados entre indivíduos da mesma origem que garantem melhores oportunidades. Dessa forma, após acumularem recursos e experiência em uma atividade considerada como um sub-emprego, os empreendedores que percorrem a trajetória $\mathrm{D}$ (figura 3 ) podem gozar de novas redes de relacionamento e prestígio na comunidade étnica. 


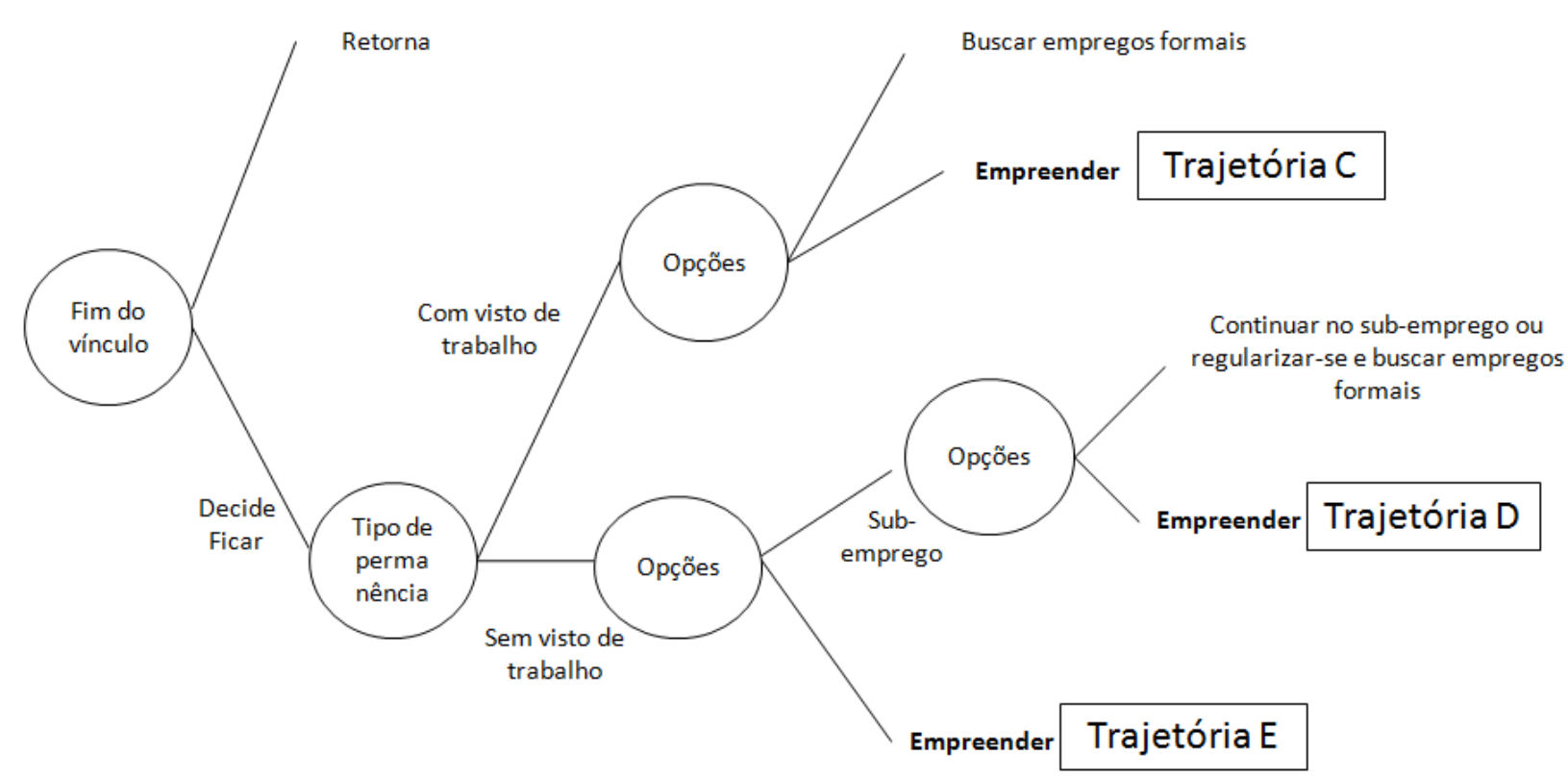

Figura 3: Possíveis atividades econômicas para os executivos expatriados ou estudantes

Fonte: Elaboração própria.

\section{Os que chegam exclusivamente de forma irregular}

As notícias repetidamente veiculadas pela imprensa sobre os riscos da imigração irregular parecem não surtirem efeito para um migrante em fuga de situação extrema, como guerra, perseguição étnica ou política, violência do narcotráfico, ou fome. Sejam latinos ou haitianos morrendo nos mares da Flórida, mexicanos no deserto fronteiriço com os EUA, ou africanos no Mar Mediterrâneo, os jornais estampam a face da realidade de muitos indivíduos desenganados com a situação do seu país (Orrenius, \& Zavodny, 2016).

De acordo com Ferreira (2016), na Europa, a atual crise migratória, conjugada com a crise econômicofinanceira, expôs as debilidades e tensões na União Européia, materializadas pela dificuldade em responder de forma coesa e eficiente às questões colocadas pela rápida chegada de um alto contingente de imigrantes.

Nos EUA, os devaneios do presidente em financiar a construção de um muro na fronteira com o México, seja fazendo o Estado vizinho pagar, ou instalando painéis solares para garantir as verbas do projeto (Welle, 2017) provam que essa tentativa desesperada de imigrar de forma irregular ainda é um dos recursos usados por indivíduos que pretendem buscar condições melhores de vida. 


\section{Trajetórias do empreendedorismo imigrante e estratégias de mercado a partir das experiências de brasileiros no exterior}

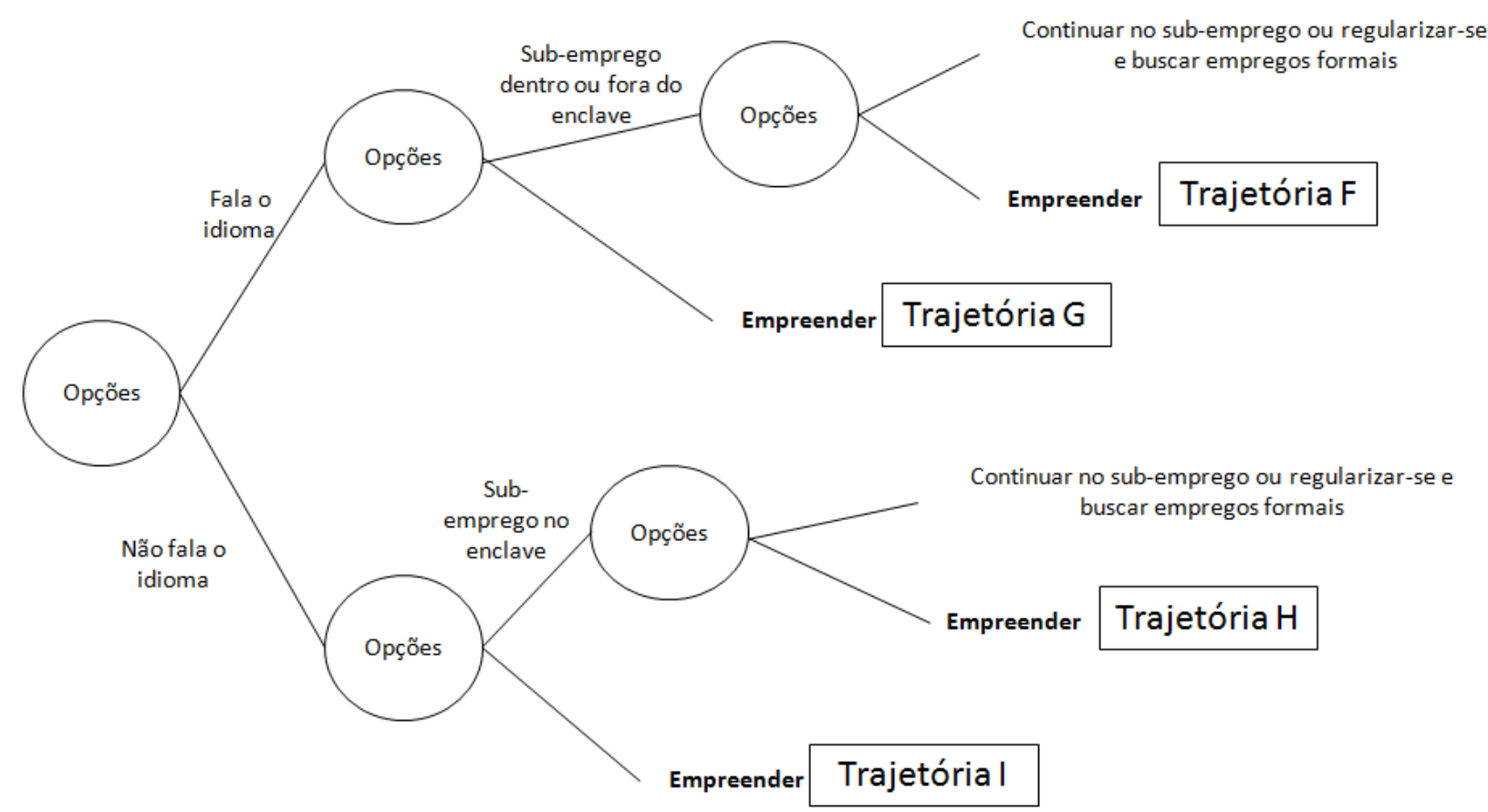

Figura 4: Possiveis atividades econômicas para os que chegam exclusivamente de forma irregular Fonte: Elaboração própria.

As trajetórias $\mathrm{G} \mathrm{e} \mathrm{I} \mathrm{(figura} \mathrm{4)} \mathrm{guardam} \mathrm{bastante} \mathrm{correlação,} \mathrm{assim} \mathrm{como} \mathrm{as} \mathrm{trajetórias} \mathrm{F} \mathrm{e} \mathrm{H}$ (figura 4). Realmente, por mais que esses pares de trajetórias pareçam semelhantes, o fato de saber falar o idioma ou não, é crucial para uma trajetória empreendedora.

Dentre as diversas questões que compõem o risco de se abrir um negócio, imediatamente após a chegada em um novo país - como o conhecimento do modus operandi local, o acesso a clientes e fornecedores - 0 domínio do idioma local certamente torna essas tarefas menos árduas. Cruz, Falcão, \& Barreto (2017) evidenciaram que cerca de $60 \%$ dos empreendedores brasileiros na Flórida - EUA não tinham conhecimento sobre a legislação local e tampouco sabiam sobre as particularidades dos clientes antes de abrirem seus negócios. Os mesmos relatarem também ter tido dificuldades de entender o funcionamento das redes de fornecedores locais. Muitas das dificuldades enfrentadas foram decorrentes de baixo grau de proficiência na língua local.

Diante das limitações de criar um negócio sem conhecer a dinâmica dos negócios e, além de tudo não dominar o idioma local, configura-se um cenário de negócios onde as oportunidades para estes indivíduos estarão exclusivamente dentro dos enclaves, caso eles existam na região de destino do imigrante. Isso talvez justifique, no caso dos brasileiros, a quantidade de imigrantes que se instalaram inicialmente na gelada cidade de Boston - MA. Os relatos dos empreendedores entrevistados que iniciaram sua jornada nos EUA por aquela cidade ganhavam tons de emoção quando eles declaravam que "não viam a hora de poder sair daquele frio e ir para a Flórida". Apesar de não ter sido destacado pelos entrevistados, a dificuldade de se comunicar em inglês certamente foi um fator decisivo, pois a comunidade em Boston é muito maior do que em qualquer outra região dos EUA, até porque se baseou em regiões onde a colonização portuguesa já estava presente.

Assim, sendo restringidos a operarem apenas no enclave étnico, os empreendedores que percorrem a trajetória I (figura 4) têm limitações de atuação. Portes e Zhou (1992) destacaram o enclave como um porto seguro para quem quer empreender de forma apressada, mas também deixaram claro que o capital social (Bourdieu, 1986) que as redes de imigrantes detêm é fundamental para o surgimento desses negócios. No 


\section{Eduardo Picanç,o Cruz, Roberto Pessoa de Queiroz Falcão, Rafael Cuba Mancebo e Andrea Ribeiro Carvalho de Castro}

caso dos brasileiros, foram identificadas ações de 'sabotagens' entre os empreendedores imigrantes que os viam como ameaças. Diferentemente, os dominicanos em Nova lorque, cubanos em Miami e chineses em Nova lorque, descritos por Portes e Zhou (1992), apresentavam um comportamento mais solidário do que os observados pelos pesquisadores nas viagens ao campo de estudo, ao pesquisarem as comunidades brasileiras. Nesse sentido a trajetória $G$ (figura 4) permite adotar uma estratégia de fugir do enclave, como relatada por alguns empresários entrevistados, que manifestam uma desconfiança perante seus compatriotas ou até repulsa à cultura de "levar vantagem" do brasileiro.

As trajetórias $\mathrm{F} \mathrm{e} \mathrm{H}$ (figura 4) praticamente se equivalem, sendo a questão principal as experiências de vida que os imigrantes tiveram nesses primeiros anos em terras estrangeiras. Nesse caso, como empreendedor que experimenta a trajetória $\mathrm{H}$ (figura 4) provavelmente teria transitado o tempo todo no enclave, a orientação estratégica seria continuar no enclave, mas se o mesmo se envolveu com a comunidade local, aprendeu com densidade o idioma, também estaria apto a buscar uma oportunidade de negócios fora do enclave - como o indivíduo da trajetória F(figura 4).

Sobre empreender fora do enclave, Sales e Loureiro (2016) destacam, e as evidencias empíricas servem como forma de confirmação por triangulação, que os filhos dos imigrantes ( $2^{a}$ geração ou étnicos) têm muito menos vínculos com a comunidade étnica ou com o país natal dos pais - isso também pode provocar uma estratégia de 'fuga do enclave'.

\section{Considerações finais}

Apesar de grande parte da literatura de empreendedorismo internacional e de internacionalização de negócios enfocarem startups tecnológicas, bornglobals e INVs, sabe-se que grande parte dos negócios criados por imigrantes são comércios locais, restaurantes étnicos, intensivos em mão de obra (em geral familiar) que contam, principalmente, com os enclaves étnicos como estratégia de inserção no mercado.

Lembrando que o objetivo principal deste ensaio teórico foi o de identificar diferentes trajetórias de empreendedores imigrantes que são ilustradas através de comportamentos, os autores valeram-se tanto de observações empíricas quanto da literatura do tema para gerar o modelo explicativo em forma de árvore apresentado na figura 1. Este framework teórico tem relevância devido à lacuna teórica apontada por Portes e Zhou (1992), Zhou (2004) e Aliaga-Isla e Rialp (2013) acerca da necessidade de um modelo teórico que explique possíveis perfis dos empresários imigrantes, destacando as relações entre suas redes, conformadas em comunidades étnicas e transnacionais. Vale ressaltar que o presente ensaio configura-se como uma tentativa inicial de se organizar as trajetórias de imigração que findam em atividades empreendedoras. Contudo não se pretende esgotar o tema. Muito pelo contrário, os autores acreditam que 0 ensaio pode estimular o debate sobre a diáspora de diversas etnias, que têm motivações diferentes, a depender do tempo, motivo e local que imigram.

As evidências recolhidas pelos autores sugerem que a imigração começa a partir de três dimensões: a primeira é composta por aqueles orientados por perspectivas concretas de imigração, a segunda é caracterizada pelos executivos e estudantes que, teoricamente, experimentam uma imigração temporária e a terceira dimensão envolve aqueles que vivenciam trajetórias irregulares de imigração.

Uma das limitações do presente estudo deriva da inexistência de referencial teórico robusto relativo às trajetórias empreendedoras de imigrantes. Tomando como exemplo a imigração brasileira Margolis (1995), Sales (2005), Sasaki (2006) e Bloem (2015), entre outros, dão mais ênfase as trajetórias de imigração do que a atividade empreendedora em si. Portanto os autores tiveram que se valer de suas experiências empíricas, conjugadas com inspirações da literatura acadêmica no tema.

Como implicação teórica, o ensaio abre espaço para uma linha temática de investigação multidisciplinar de empreendedorismo imigrante ligada às histórias de vida e às trajetórias empreendedoras.

Quanto à suas implicações gerenciais espera-se também contribuir para reflexão no tema e iluminar o caminho para futuros empreendedores que queiram se aventurar no exterior. 


\section{Trajetórias do empreendedorismo imigrante e estratégias de mercado a partir das experiências de brasileiros no exterior}

No entanto, como este é um ensaio inicial, não significa que se possa atribuir um caráter determinista ou exaustivo às categorizações realizadas. Estudos futuros seriam fundamentais e necessários para validar 0 caráter amplo da construção, incluindo imigrantes de outras nacionalidades assim como utilizando outras abordagens metodológicas. Seguindo as recomendações de Dunne (2011) para estudos futuros, os autores deste artigo ainda sugerem a realização de amostragem propositiva, a análise de casos negativos, que não se encaixem nas trajetórias propostas, e o teste do modelo de trajetórias para os diferentes contextos étnicos, haja vista que os autores reconhecem que grande parte de suas observações foram realizadas no seio de comunidades de imigrantes brasileiros, embora confrontadas com a literatura relativa à outras etnias.

\section{Referências}

Aliaga-Isla, R., \& Rialp, A. (2013). Systematic review of immigrant entrepreneurship literature: previous findings and ways forward. Entrepreneurship \& Regional Development, 25(9-10),819-844.

Barney, J. (1991). Firm resources and sustained competitive advantage. Journal of management, 17(1), 99-120.

Bloem, T. M. (2015). Impacts of Brazilian Business and Brazilian Immigrant Organizations in South Florida. M.Sc. Thesis. A Thesis Submitted to the Faculty of the Center for Latin American Studies In Partial Fulfillment of the Requirements For the Degree of Master of Arts In the Graduate College The University of Arizona.

Bonacich, E. (1973). A theory of middleman minorities. American sociological review, 583-594.

Borjas, G. (2017). The Immigration Debate We Need. The New York Times, Feb, 27.

Born, C. (2001). Gênero, trajetória de vida e biografia: desafios metodológicos e resultados empíricos. Sociologias, 3(5).

Bourdieu, P. (1986). The Forms of Capital.In handbook of theory and research for the sociology of education. Edited by: Richardson J.

Brasil - Ministério do Turismo. (2010). Turismo de Estudos e Intercâmbio: orientações básicas. Ministério do Turismo, Secretaria Nacional de Políticas de Turismo, Departamento de Estruturação, Articulação e Ordenamento Turístico, Coordenação Geral de Segmentação. - 2.ed. - Brasília: Ministério do Turismo.

Brinkerhoff, J. M. (2016) Institutional Reform and Diaspora Entrepreneurs: The In-Between Advantage.Oxford University Press.

Caligiuri, P. M. (2000). Selecting expatriates for personality characteristics: A moderating effect of personality on the relationship between host national contact and cross-cultural adjustment. MIR: Management International Review, 61-80.

Carvalho e Silva, A. de; C. Yen-Tsang. (2015). Tem Comida Chinesa no Prato dos Brasileiros: Como Empreendem os Imigrantes Chineses no Brasil? In: XXXIX Encontro da ANPAD - EnANPAD, 2015, Belo Horizonte. Anais do XXXIX Encontro da ANPAD - EnANPAD. Belo Horizonte.

Cruz, E. P., Falcão, R. P. D. Q., \& Barreto, C. R. (2017). Estudo exploratório do empreendedorismo imigrante brasileiro em Pompano Beach e Orlando-EUA. Gestão \& Planejamento-G\&P, 18.

Cruz, E. P., Jesus, D. M. O. de, Falcão, R. P. de Q., Lopes, L. A. C., Petri, F. C., Melo, Y. M. de, Junior, R. M. de S. (2016). Relatório de pesquisa sobre os brasileiros na Austrália. Niterói, RJ: Departamento de Empreendedorismo e Gestão da Universidade Federal Fluminense.

De Holanda, S. B., Summ, G. H., \& Monteiro, P. M. (2012). Roots of Brazil.Univ.ofNotreDame.

Drori, I., Honig, B., \& Wright, M. (2009). Transnational entrepreneurship: An emergent field of study. Entrepreneurship Theory and Practice, 33(5), 1001-1022. 
Dunne, C. (2011). The place of the literature review in grounded theory research. International Journal of Social Research Methodology, 14(2), 111-124.

Elo, M. \&Volovelsky, E. K. (2016).Jewish diaspora entrepreneurs - the impact of religion on opportunity exploration and exploitation. International Journal of Entrepreneurship and Small Business, in press.

Elo, M., Harima, A., \&Freiling, J. (2015). To Try or Not to Try?A story of diaspora entrepreneurship. The Future of Global Organizing. Progress in International Business Research, 10, 283-293.

Emontspool, J., \&Servais, P. (2016). Cross-border entrepreneurship in a global world: a critical reconceptualization. European Journal of International Management.

Ferreira, J. (2016). A União Europeia e a imigração irregular no contexto da segurança humana.

Filion, L. J. (1999). Empreendedorismo: empreendedores e proprietários-gerentes de pequenos negócios. Revista de Administração da Universidade de São Paulo, 34(2).

Freyre, G. (1986). Casa-grande e senzala (Vol. 351). Univ of California Press.

Glosario sobre Migración. (2006). Derecho Internacional sobre Migracion. Organización Internacional del Migrante (OIM).

Gold, S. J., \& Light, I. (2000).Ethnic economies and social policy. Research in social movements, conflicts and change, 22, 165-91.

Gordon, M. M. (1961). Assimilation in America: Theory and reality. Daedalus, 90(2), 263-285.

Gorji, M. B., \& Rahimian, P. (2011). The study of barriers to entrepreneurship in men and women. Australian Journal of Business and Management Research, 1(9), 31.

Halter, M. (2007). Cultura econômica do empreendimento étnico: caminhos da imigração ao empreendedorismo. Revista de Administração de Empresas, 47(1), 116-123.

Ibrahim, G., \& Galt, V. (2003). Ethnic business development: Toward a theoretical synthesis and policy framework. Journal of Economic Issues, 37(4), 1107-1119.

Johanson, J. \& Vahlne, J.E. (1977). The internationalization process of the firm: a model of knowledge development and increasing market commitment. Journal of International Business Studies, Vol. 8 No. 1, pp. 23-32.

Johanson, J. \& Vahlne, J.E. (2009). The Uppsala internationalization process model revisited: from liability of foreignness to liability of outsidership. Journal of International Business Studies, Vol. 40 No. 3, pp. 41121.

Kloosterman, R., \& Rath, J. (2001). Immigrant entrepreneurs in advanced economies: mixed embeddedness further explored. Journal of Ethnic and Migration Studies, 27(2), 189-201.

Kloosterman, R., Van der Leun, J., \&Rath, J. (1998). Across the border: Immigrants' economic opportunities, social capital and informal business activities. Journal of ethnic and migration studies, 24(2), 249-268.

Knight, J. (2015). Migrant employment in the ethnic economy: why do some migrants become ethnic entrepreneurs and others co-ethnic workers?. Journal of International Migration and Integration, 16(3), 575.

Kohli, M. (1985). Die Institutionalisierung des Lebenslaufs. Historische Befunde und theoretische Argumente. Kölner Zeitschrift für soziologie und sozialpsychologie, 37(1), 1-29.

Ley, D. (2017). Global China and the making of Vancouver's residential property market. International Journal of Housing Policy, 17(1), 15-34.

Light, I., Bhachu, P., \&Karageorgis, S. (1993). Migration networks and immigrant entrepreneurship. Immigration \& entrepreneurship: Culture, capital, and ethnic networks, 25-50.

ISSN 2318-9231

CGE * v .5 * n. 2 * Mai-Ago 2017 * 37-54 


\section{Trajetórias do empreendedorismo imigrante e estratégias de mercado a partir das experiências de brasileiros no exterior}

Light, I., Sabagh, G., Bozorgmehr, M., \& Der-Martirosian, C. (1994). Beyond the ethnic enclave economy. Social Problems, 41(1), 65-80.

Logan, J. R., Zhang, W., \& Alba, R. D. (2002). Immigrant enclaves and ethnic communities in New York and Los Angeles. American sociological review, 299-322.

Madsen, T. K., \& Servais, P. (1997). The internationalization of born globals: an evolutionary process?. International Business Review, 6(6), 561-583.

Margolis, M. L. (1995). Transnationalism and popular culture: the case of Brazilian immigrants in the United States. The Journal of Popular Culture, 29(1), 29-41.

Martes, A. C. B., \& Rodriguez, C. L. (2004). Afiliação religiosa e empreendedorismo étnico: o caso dos brasileiros nos Estados Unidos. Revista de Administração Contemporânea, 8(3), 117-140.

Massey, D. S., Arango, J., Hugo, G., Kouaouci, A., Pellegrino, A., \& Taylor, J. E. (1993). Theories of international migration: A review and appraisal. Population and development review, 431-466.

Ma, Z., Zhao, S., Wang, T., \& Lee, Y. (2013). An overview of contemporary ethnic entrepreneurship studies: themes and relationships. International Journal of Entrepreneurial Behavior \& Research, 19(1), 32-52.

McCracken, G. (1988). The Long Interview, Beverly Hills, CA: Sage.

McDougall, P.P. and Oviatt, B.M. (2000) 'International entrepreneurship: the intersection of two research paths', Academy of Management Journal, 43: 902-908.

Meneghetti, F. K. (2011). O que é um ensaio-teórico?. RAC-Revista de Administração Contemporânea, 15(2).

Mintzberg, H. (1988). Generic strategies: toward a comprehensive framework. Advances in strategic management, 5(1), 1-67.

Orrenius, P. M. \& Zavodny, M. (2016). Irregular immigration in the European Union. European Policy Analysis, Swedish Institute for European Policy Studies, ISSUE 2016:2.

Oviatt, B.M. and McDougall, P.P. (1994) 'Toward a theory of international new ventures', Journal of International Business Studies, 25(1): 45-64.

Portes, A., \& Zhou, M. (1992).Gaining the upper hand: Economic mobility among immigrant and domestic minorities. Ethnicand Racial Studies, 15, 491-522.

Quaino, L. (2015). Investimento EB-5 para obter 'greencard' nos EUA cresce no Brasil. G1, caderno de economia. Retrievedfrom http://g1.globo.com/economia/noticia/2015/03/investimento-eb-5-para-obtergreen-card-nos-eua-cresce-no-brasil.html

Riddle, L. (2008). Diasporas: Exploring their development potential. ESR Review, 10(2), 28.

Rocha, A. D., Esteves, F., Mello, R. C. D., \& Silva, J. F. D. (2015). Diasporic and transnational internationalization: the case of Brazilian martial arts. BAR-Brazilian Administration Review, 12(4), 403420.

Sales, T. (2005). A organização dos imigrantes brasileiros em Boston, EUA. São Paulo em perspectiva, 19(3), 44-54.

Sales, T., \& Loureiro, M. (2016). Imigrantes brasileiros adolescentes e de segunda geração em Massachusetts, EUA. Anais, 1-37.

Santos, A. L. (2013). Antes, de lá pra cá. Agora, daqui pra lá: fluxos migratórios do Brasil para Portugal a partir de 1980. GEOUSP: Espaço e Tempo (Online), (34), 195-210. 
Sasaki, E. (2006). A imigração para o Japão. Estudos avançados, 20(57), 99-117.

Saxenian, A. (2007). The new argonauts: Regional advantage in a global economy. Harvard University Press.

Schoof, U. (2006). Stimulating Youth Entrepreneurship: Barriers and incentives to enterprise start-ups by young people (No. 993881573402676). International Labour Organization.

Teixeira, P. E., Braga, A. M. D. C., \& Baeninger, R. (2012). Migrações: implicações passadas, presentes e futuras. Marília: Oficina Universitária.

Tung, R. L. (2008). The cross-cultural research imperative: The need to balance cross-national and intranational diversity. Journal of International Business Studies, 39(1), 41-46.

Vilicic, F. (2017). Vale do Silício desafia Trump e batalhará para manter imigrantes. Revista Veja. Recuperado em 25 abril, 2017, de http://veja.abril.com.br/blog/a-origem-dos-bytes/vale-do-silicio-desafiatrump-e-batalhara-para-manter-imigrantes/

Volery, T. (2007). Ethnic entrepreneurship: a theoretical framework. Handbook of Research on Ethnic Minority Entrepreneurship, 1, 30-41.

Welle, D. (2017). Trump propõe painéis solares em muro na fronteira com México. Caderno Mundo - G1. Recuperado em 07 de julho de 2017, de http://g1.globo.com/mundo/noticia/trump-propoe-paineis-solaresem-muro-na-fronteira-com-mexico.ghtml

Whichfranchise.Com. (2016). Buy a franchise and settle down in the USA. Recuperado em 25 abril, 2017 , de http://www.whichfranchise.com/feature_template.cfm?featureld=355

Zhou, M. (2004). The Role of the Enclave Economy in Immigrant Adaptation and Community Building: The case of New York's Chinatown. In: Immigrant and Minority Entrepreneurship. The Continuous Rebirth of American Communities.John Sibley Butler \& GeorgeKozmetsky.PRAGER: London.

Zolin, R., \& Schlosser, F.(2013).Characteristics of immigrant entrepreneurs \& their involvement in international new ventures. Thunderbird International Business Review, 55(3), 271-284. 